\title{
Nghiên cứu ứng dụng phân hữu cơ vi sinh trong sản xuất rau an toàn
}

\section{Research on application of an organic fertilizer in safe vegetable production}

\author{
Nguyễn Hồng Thủy ${ }^{1 *}$ \\ ${ }^{1}$ Trường Đại học Tiền Giang, Việt Nam \\ "Tác giả liên hệ, Email: nguyenhongthuy @ tgu.edu.vn
}

THÔNG TIN

DOI: 10.46223/HCMCOUJS. tech.vi.16.1.1403.2021

Ngày nhận: 18/01/2021

Ngày nhận lại: 09/04/2021

Duyệt đăng: 28/04/2021

Tì khóa:

chế phẩm sinh học; chuyển giao công nghệ; chất lượng; rau an toàn

\section{TÓM TẮT}

Tại Tiền Giang, một sản phẩm khoa học công nghệ của Trung tâm Đấu tranh sinh học (trực thuộc Viện Bảo vệ thực vật) chế phẩm bón gốc (Phân hữu cơ vi sinh Bioroot) sau đây gọi tắt là Bioroot - đã được chuyển giao cho Trung tâm Kỹ thuật và Công nghệ sinh học (trực thuộc Sở Khoa học và Công nghệ Tiền Giang) từ 12/2006 đến tháng 12/2010 trong khuôn khổ Dự án nông thôn miền núi "Xây dựng mô hình sản xuất và ứng dụng chế phẩm sinh học phục vụ sản xuất rau - quả an toàn" nhằm góp phần đẩy mạnh sản xuất nông nghiệp theo hướng sản xuất hàng hóa có chất lượng cao, an toàn cho người tiêu dùng và môi trường. Bioroot sau đó tiếp tục được nghiên cứu ứng dụng ở vùng rau chuyên canh của tỉnh Long An từ năm 2012-2015 cùng các loại chế phẩm sinh học khác trên đối tượng rau ăn lá, rau gia vị, rau ăn quả, trong đề tài nghiên cứu khoa học "Xây dựng mô hình sản xuất rau an toàn đạt chứng nhận VietGAP tại ba huyện Cần Đước, Cần Giuộc, Đức Hòa tỉnh Long An" nhằm tìm ra các loại chế phẩm sinh học có khả năng hỗ trợ duy trì năng suất, chất lượng rau khi phải giảm lượng phân đạm bón cho cây, nhất là vào giai đoạn cuối và đảm bảo thời gian cách ly phân đạm trước khi thu hoạch để các loại rau ăn lá, rau gia vị, rau ăn quả phù hợp yêu cầu vệ sinh an toàn thực phẩm của tiêu chuẩn VietGAP. Đây là một sản phẩm khoa học công nghệ được chuyển giao thông qua một dự án nông thôn miền núi từ cơ quan nghiên cứu ứng dụng cấp trung ương xuống cơ quan nghiên cứu ứng dụng cấp địa phương. Trong thời gian dài, sản phẩm đã được địa phương tiếp nhận, thử nghiệm, nghiên cứu ứng dụng trên nhiều đối tương cây trồng khác nhau cho thấy sự phù hợp của sản phẩm này với nhiều chủng loại cây trồng tại địa phương, đồng thời cũng phù hợp với các tiêu chí sản xuất an toàn theo tiêu chuẩn VietGAP.

\section{ABSTRACT}

In Tien Giang, a scientific and technological product of the Center for Biological Struggle (under the Institute of Plant 
Keywords:

biofertilizer; quality; safe vegetable; technology transfer
Protection) - base fertilizer (Bioroot organic biofertilizer) hereinafter referred to as Bioroot - was transferred and assigned to the Center for Engineering and Biotechnology (under Tien Giang Department of Science and Technology) from December 2006 to December 2010 in the framework of the mountainous rural project "Building production models and using bioproducts for safe vegetable - fruit production" in order to contribute to promoting agricultural production in the direction of producing high quality goods, safe for consumers and the environment. Bioroot then continued to be studied and applied in specialized vegetable areas of Long An province from 2012 - 2015 together with other bioproducts on leaf vegetables, spice vegetables, fruit vegetables, in the scientific research project "Building a model of safe vegetable production with VietGAP certification in three districts of Can Duoc, Can Giuoc, Duc Hoa, Long An province" in order to find out bioproducts that can help maintain vegetable productivity and quality when it is necessary to reduce the amount of nitrogenous fertilizer for plants, especially in the final stage and ensure the time to isolate nitrogen fertilizers before harvest so that the leaf vegetables, spice vegetables, fruit vegetables are suitable for hygiene and safety requirements for food of VietGAP standard. This is a scientific and technological product transferred through a mountainous rural project from a central research agency to a local applied research agency. For a long time, the product has been received, tested, researched and applied locally on many different crops, showing its suitability with many types of local crops, at the same time, also in accordance with VietGAP standards of safe production.

\section{Giới thiệu}

Rau là thực phẩm không thể thiếu trong bữa ăn hàng ngày của mọi người. Sản xuất rau ở nước ta nói chung và tại Tiền Giang nói riêng về cơ bản đáp ứng nhu cầu tiêu thụ rau xanh của người dân, tuy nhiên, kỹ thuật trồng rau thâm canh sử dụng nhiều phân bón hóa học, hóa chất bảo vệ thực vật, chất điều hòa sinh trưởng chưa đảm bảo tiêu chuẩn an toàn vệ sinh thực phẩm.

Nhiều năm qua, tại Tiền Giang, nhiều biện pháp quản lý và kỹ thuật đã được nghiên cứu ứng dụng để sản xuất ra sản phẩm rau an toàn phục vụ người dân. Tính đến năm 2020, Tiền Giang có tổng diện tích rau đạt chứng nhận VietGAP trên 150 ha, cung cấp sản lượng hằng năm trên 18 ngàn tấn (Sy Nguyen, 2020). Công nghệ thủy canh được nghiên cứu ứng dụng tại Tiền giang vào năm 2016 với bảy giàn thuỷ canh hồi lưu quy mô sản xuất, một giàn thuỷ canh ngập chìm tạm thời, hai giàn thuỷ canh nhỏ giọt quy mô sản xuất và hai giàn thuỷ canh hồi lưu quy mô gia đình được nghiên cứu, thiết lập và chuyển giao cho Trung tâm Kỹ thuật và Công nghệ Sinh học Tiền Giang (T. T. N. Tran, 2016), sau đó, tiếp tục được nghiên cứu ứng dụng, chuyển giao trong các dự án sản xuất thử nghiệm trên địa bàn Thị trấn Chợ Gạo $(\mathrm{P}$. H. Tran, 2019) và huyện Cái Bè (Ho, 2019), Tiền Giang. Công nghệ khí canh của Trung tâm Nghiên cứu ứng dụng và Dịch vụ Khoa học công nghệ - Sở Khoa học và Công nghệ Tiền Giang được nghiên cứu ứng dụng và chuyển giao cho người dân thành phố trồng rau xanh với dung dịch chất dinh dưỡng sẽ 
được phun sương từ trên xuống dưới, lượng dung dịch này sau khi thấm đủ cho bộ rễ của cây sẽ rơi xuống bồn chứa bên dưới và tiếp tục tuần hoàn sử dụng. Dinh dưỡng được sử dụng hoàn toàn từ hữu cơ nên cây dễ hấp thu, tăng trưởng nhanh, không cần sử dụng đất trồng nên hạn chế sâu bệnh phát sinh, giảm chi phí sản xuất (T. T. T. Nguyen, 2019).

Công nghệ sản xuất chế phẩm vi sinh xử lý phế phụ liệu nông nghiệp sẵn có ở địa phương là mạt cưa sau trồng nấm, mụn xơ dừa, với bộ chủng vi sinh vật bản địa có khả năng phân giải cellulose cao tạo ra giá thể hữu cơ sạch cũng đã được nghiên cứu ứng dụng phục vụ vùng trồng rau, hoa của tỉnh $(\mathrm{D}$. $\mathrm{H}$. Tran, 2016). Nhà màng được thiết kế và chế tạo với đầy đủ các yếu tố quan trọng để việc chăm sóc, bón phân, tưới nước được thực hiện theo đúng quy trình kỹ thuật, kiểm soát được nhiều yếu tố như mưa, nắng, gió, ngăn chặn xâm nhập của nhiều loại côn trùng ... qua đó làm giảm chi phí đầu tư, công lao động và hạn chế đáng kể sử dụng thuốc BVTV. Hệ thống tưới nhỏ giọt là biện pháp tưới tiết kiệm nước nhất, giúp giảm đến 30-60\% lượng nước so với phương pháp tưới truyền thống. Hệ thống tưới này cung cấp nước thường xuyên, duy trì độ ẩm thích hợp theo nhu cầu sinh trưởng và phát triển của các loại cây trồng. Nhờ đó, cây sinh trưởng tốt, phát triển nhanh, đạt năng suất cao, góp phần ngăn chặn sự phát triển của cỏ dại quanh gốc cây và sâu bệnh vì lượng nước chỉ cung cấp làm ẩm gốc cây. Biện pháp kỹ thuật "Nhà màng kết hợp hệ thống tưới nhỏ giọt" đã được Le (2016) nghiên cứu ứng dụng thành công tại Trung tâm Kỹ thuật và Công nghệ sinh học - Sở Khoa học và Công nghệ Tiền Giang, sau đó được tổ chức nhân rộng trên địa bàn 11 huyện, thị xã, thành phố của tỉnh Tiền Giang và chuyển giao thành công cho các tỉnh Hậu Giang, Cần Thơ, Vĩnh Long, Long An, Bến Tre, Bình Thuận, Thanh Hóa, góp phần mở rộng vùng sản xuất rau an toàn trong và ngoài tỉnh (T. H. Nguyen, 2018).

Sử dụng chế phẩm bón gốc là một trong những biện pháp kỹ thuật hiệu quả trong sản xuất rau an toàn. Một sản phẩm khoa học công nghệ của Trung tâm Đấu tranh sinh học (trực thuộc Viện Bảo vệ thực vật) - chế phẩm bón gốc (Phân hữu cơ vi sinh Bioroot) sau đây gọi tắt là Bioroot - đã được chuyển giao cho Trung tâm Kỹ thuật và Công nghệ sinh học (đơn vị sự nghiệp trực thuộc Sở Khoa học và Công nghệ Tiền Giang) từ 12/2006 đến tháng 12/2010 trong khuôn khổ Dự án nông thôn miền núi "Xây dựng mô hình sản xuất và ứng dụng chế phẩm sinh học phục vụ sản xuất rau - quả an toàn" nhằm góp phần đẩy mạnh sản xuất nông nghiệp theo hướng sản xuất hàng hóa có chất lượng cao, an toàn cho người tiêu dùng và môi trường $(\mathrm{H}$. $\mathrm{T}$. $\mathrm{H}$. Nguyen, 2010). Sau đó, Bioroot tiếp tục được nghiên cứu ứng dụng ở vùng rau chuyên canh của tỉnh Long An cùng các loại chế phẩm sinh học khác trên đối tượng rau ăn lá, rau gia vị, rau ăn quả, trong đề tài nghiên cứu khoa học "Xây dựng mô hình sản xuất rau an toàn đạt chứng nhận VietGAP tại ba huyện Cần Đước, Cần Giuộc, Đức Hòa tỉnh Long An" nhằm tìm ra các loại chế phẩm sinh học có khả năng hỗ trợ duy trì năng suất, chất lượng rau khi phải giảm lượng phân đạm bón cho cây, nhất là vào giai đoạn cuối và đảm bảo thời gian cách ly phân đạm trước khi thu hoạch để các loại rau ăn lá, rau gia vị, rau ăn quả phù hợp yêu cầu vệ sinh an toàn thực phẩm của tiêu chuẩn VietGAP (T. H. Nguyen \& Vo, 2015).

Bioroot được nghiên cứu ứng dụng trên nhiều chủng loại rau và trên nhiều địa bàn khác nhau để chứng minh sự phù hợp của sản phẩm với các vùng sản xuất rau an toàn trong và ngoài tỉnh.

\section{Vật liệu và phương pháp nghiên cứu}

\subsection{Vật liệu}

Bioroot có chứa thành phần hữu cơ $\geq 20 \%$, acid humic $\geq 3.5 \%, \mathrm{~N}_{\mathrm{ts}} \geq 0.5 \%, \mathrm{P}_{2} \mathrm{O}_{5 \mathrm{hh}} \geq 1 \%$, $\mathrm{K}_{2} \mathrm{O}_{\mathrm{hh}} \geq 0.5 \%, \mathrm{CaO} \geq 1.5 \%, \mathrm{MgO} \geq 1.2 \%, \mathrm{~S} \geq 0.5 \%$, Trichoderma: $\geq 1 \times 10^{8} \mathrm{CFU} /$ gram, Vi sinh 
vật (VSV) phân giải cellulose: $\geq 1 \times 10^{8} \mathrm{CFU} /$ gram, VSV phân giải lân: $\geq 1 \times 10^{8} \mathrm{CFU} /$ gram, VSV cố định đạm: $\geq 1 \times 10^{8} \mathrm{CFU} /$ gram, Vi sinh ức chế bệnh: $\geq 1 \times 10^{8} \mathrm{CFU} /$ gram, thảo mộc chứa Saponin.

\subsection{Phưong pháp nghiên cứu}

2.2.1. Nghiên cứu ứng dụng chế phẩm sinh học phục vụ sản xuất rau - quả an toàn

Nghiên cứu ứng dụng chế phẩm này được triển khai trên hầu hết các địa bàn thuộc bảy huyện/thị xã/thành phố, 19 xã của tỉnh Tiền Giang với tổng diện tích là 183.77 ha trên các loại: rau ăn lá (cải tùa xại, cái xanh, cải ná, cải ngọt bông, cải ngọt, cải bắp, cải bông, cải dún, cải thìa, củ cải trắng, tần $\hat{o}$, mồng tơi, dền, bù ngót, hành, hẹ, xà lách, ngò rí, rau quế, rau húng cây, rau diếp cá, rau má), rau ăn quả (bầu, bí đao, bi hồ lô, mướp, đậu cove, đậu đũa, đậu bắp, cà chua, cà tím, ơt, dura hấu, dura leo, khổ qua); hoa (huệ, vạn thọ); cây ăn quả (bưởi, cam, vú sũu).

Phuoong pháp xủ lý chế phẩm: bón lót một lần trước khi trồng hoặc trước khi bồi đất lần 01; tiến hành rắc chế phẩm rồi trộn đều với đất trong rãnh trồng, rồi dùng đất bột phủ đều lên trên và tưới nhẹ. Có thể phối hợp cùng với việc bón phân lót cho cây ngay khi trồng.

Liều lượng: đối với các loại cây ngắn ngày sử dụng 0.5 tấn/ha.

Ghi nhận các chỉ tiêu:

- Sự gia tăng chiều cao cây;

- Quan sát (cảm quan): màu sắc lá, độ dày lá, độ cứng cây; có ít hoặc nhiều sâu bệnh tấn công, gây hại;

- Bệnh: quan sát triệu chứng héo rũ/chết cây con/chạy dây để tính tỷ lệ.

Thời gian ghi nhận chỉ tiêu: trung bình là 07 ngày/lần, nếu loại rau có thời gian sinh trưởng ngắn thì 03-04 ngày/lần.

- Ghi nhận năm điểm theo đường chéo góc trên cá thể cố định (mỗi điểm ghi nhận khoảng 05 - 10 cá thể) hoặc ghi nhận trên khung với diện tích khung cố định (khung $0.4 m \times 0.5 m$ hoặc khung $0.2 m \times 0.2 m)$.

- Mỗi nghiệm thức ghi nhận ít nhất 30 điểm cố định hoặc 30 khung cố định.

2.2.2. Nghiên cưu ứng dụng các loại chế phẩm sinh học, trong đó có Bioroot, nhằm giảm luợng phân Ure (đạm) bón cho các loại rau ăn lá, rau gia vị, rau ăn quả

* Cải ngọt

- Bố trí 05 nghiệm thức, 03 lần lặp lại, diện tích ô khảo nghiệm: $11.25 \mathrm{~m}^{2}(\mathrm{~S}=1.5 \mathrm{~m} \mathrm{x}$ $7.5 \mathrm{~m})$.

\section{Bảng 1}

Bảng tổng hợp lượng phân bón cây Cải ngọt

\begin{tabular}{lcccccc}
\hline & \multicolumn{5}{c}{ Lượng phân cho mỗi ô lặp lại 11.25m² } \\
\cline { 2 - 6 } Nghiệm thức & Bón lót & $\begin{array}{c}\text { 4 ngày sau cấy } \\
\text { (NSC) }\end{array}$ & 10 NSC & 13 NSC & 16 NSC & 18 NSC \\
\hline
\end{tabular}

ĐC Phân gà xử lý Ure: $0.55 \mathrm{~kg} \quad$ Ure: $0.55 \mathrm{~kg}$

Humix: $0.85 \mathrm{~kg}$ 


\begin{tabular}{llcllll}
\hline & \multicolumn{5}{c}{ Lượng phân cho mỗi ô lặp lại 11.25m² } \\
\cline { 2 - 6 } Nghiệm thức & Bón lót & $\begin{array}{c}4 \text { ngày sau cấy } \\
\text { (NSC) }\end{array}$ & $10 \mathrm{NSC}$ & $13 \mathrm{NSC}$ & $16 \mathrm{NSC}$ & $18 \mathrm{NSC}$ \\
\hline
\end{tabular}

Lân: $0.85 \mathrm{~kg}$

\begin{tabular}{llcc} 
A & Phân gà xử lý & Ure: $0.55 \mathrm{~kg}$ & Ure: $0.30 \mathrm{~kg}$ \\
Humix: $0.85 \mathrm{~kg}$ & Phân đầu gà: \\
& Lân: $0.85 \mathrm{~kg}$ & $0.85 \mathrm{~kg}$ & \\
\hline
\end{tabular}

Lân: $0.85 \mathrm{~kg}$

Agribio: Tỷ lệ

Ure: $0.55 \mathrm{~kg}$

$\begin{array}{llc}\text { B (Agribio) } & \begin{array}{l}\text { Agri:nước } \\ (1 m l: 300 m l)\end{array} & \begin{array}{c}\text { Agribio: Tỷ lệ } \\ \text { Agri: nước }\end{array} \text { Ure: 0.40kg } \\ & \begin{array}{l}\text { Phun 03 ngày } \\ \text { trức khi trồng. }\end{array} & (1 \mathrm{ml}: 1500 \mathrm{~m}) \\ & & \end{array}$

\begin{tabular}{ll} 
C (Bioroot) $\quad \begin{array}{l}\text { Lân: } 0.85 \mathrm{~kg} \\
\text { Bioroot: } 0.85 \mathrm{~kg}\end{array} \quad$ Ure: $0.55 \mathrm{~kg} \quad$ Ure: $0.40 \mathrm{~kg}$ \\
\hline
\end{tabular}

\begin{tabular}{|c|c|c|c|c|c|c|}
\hline \multirow[b]{3}{*}{ D (Bioking) } & \multicolumn{6}{|c|}{ Ure: $0.30 \mathrm{~kg}$} \\
\hline & Lân: $0.85 \mathrm{~kg}$ & Ure: $0.25 \mathrm{~kg}$ & VVS: $15 \mathrm{ml}$ & $\begin{array}{c}\text { Ure: } \\
\text { 0.10kg }\end{array}$ & VVS lá: & VVS lá: \\
\hline & $\begin{array}{l}\text { VVS: } 20 \mathrm{ml} \\
\text { (tuới vào đất) }\end{array}$ & $\begin{array}{l}\text { VVS: } 15 \mathrm{ml} \\
\text { (tuoói vào rễ) }\end{array}$ & $\begin{array}{c}\text { rê̂) } \\
\text { VVS lá: } \\
\text { 10ml } \\
(\text { phun })\end{array}$ & $\begin{array}{l}\text { VVS lá: } \\
\text { 20ml } \\
\text { (phun) }\end{array}$ & $\begin{array}{c}20 \mathrm{ml} \\
\text { (phun) }\end{array}$ & $\begin{array}{c}20 \mathrm{ml} \\
\text { (phun) }\end{array}$ \\
\hline
\end{tabular}

Ghi chú:

+ NSC: ngày sau cấy;

+ĐC: nghiệm thức đối chứng (công thức bón của nông dân);

+ A: nghiệm thức cái tiến tù công thức bón của nông dân, bổ sung thêm lương hũu co đầu gà vào làn bón thúc đầu và giảm $1 / 2$ lượng phân đạm vào lần bón phân cuối; phân cuối;

+ B: nghiệm thức bón kết hợp với phân hưu cơ vi sinh Agribio và giảm 1/4 lương phân đạm vào làn bón

+ C: nghiệm thức sủ dụng chế phẩm bón gốc (Bioroot) để bón lót và sẽ giảm 1/4 lương phân đạm vào lần bón phân cuối;

+ D: nghiệm thức sủ dụng phân bón sinh học Bioking để phun, tuới và giảm 40\% tổng luợng phân đạm.

Nguồn: Tác giả tổng hợp

* Húng cây

- Bố trí 04 nghiệm thức, 03 lần lặp lại, diện tích ô khảo nghiệm: $22.4 \mathrm{~m}^{2}$ ( $\mathrm{S}=1.6 \mathrm{~m} x$ $14 \mathrm{~m})$. 


\section{Bảng 2}

Bảng tổng hợp lượng phân bón cây Húng cây

\section{Lượng phân cho mỗi ô lặp lại $22.4 m^{2}$}

\begin{tabular}{|c|c|c|c|c|}
\hline Nghiệm thức & Tưới lót & $10 \mathrm{NSC}$ & 20NSC & 30NSC \\
\hline ĐC & $\begin{array}{c}\text { Lân: } 2.24 \mathrm{~kg} \\
\text { Phân gà xử lý Humix: } \\
\text { 4.48kg }\end{array}$ & Ure: $0.3584 \mathrm{~kg}$ & Ure: $0.448 \mathrm{~kg}$ & Ure: $0.224 \mathrm{~kg}$ \\
\hline \multirow[b]{2}{*}{ A } & Lân: $2.24 \mathrm{~kg}$ & Ure: $0.3584 \mathrm{~kg}$ & \multirow[b]{2}{*}{ Ure: $0.448 \mathrm{~kg}$} & \multirow[b]{2}{*}{ Ure: $0.112 \mathrm{~kg}$} \\
\hline & $\begin{array}{c}\text { Phân gà xử lý Humix: } \\
4.48 \mathrm{~kg}\end{array}$ & $\begin{array}{l}\text { Phân gà xử lý } \\
\text { Humix: } 4.48 \mathrm{~kg}\end{array}$ & & \\
\hline & Lân: $2.24 \mathrm{~kg}$ & Ure: $0.3584 \mathrm{~kg}$ & Ure: $0.448 \mathrm{~kg}$ & Ure: $0.112 \mathrm{~kg}$ \\
\hline B (Agribio) & $\begin{array}{l}\text { Phân gà xử lý Humix: } \\
2.24 \mathrm{~kg} \\
\text { Agribio (1:300): } 2.5 \mathrm{ml}\end{array}$ & $\begin{array}{c}\text { Agribio (1:1000): } \\
\text { 1ml }\end{array}$ & - & - \\
\hline $\mathrm{C}$ (Bioroot) & $\begin{array}{c}\text { Lân: } 1.8 \mathrm{~kg} \\
\text { Bioroot: } 4.48 \mathrm{~kg}\end{array}$ & Ure: $0.3584 \mathrm{~kg}$ & Ure: $0.448 \mathrm{~kg}$ & Ure: $0.112 \mathrm{~kg}$ \\
\hline
\end{tabular}

Ghi chú:

+ ĐC: nghiệm thức đối chứng (công thức tưới của nông dân);

+ A: nghiệm thức cải tiến tù công thức bón của nông dân, bón thêm phân hưu co vào lần bón thúc đầu, giảm 1/2 luợng phân đạm vào lần tuới phân cuối cùng; phân cuối;

+ B: nghiệm thức bón kết hợp với phân hưu co vi sinh Agribio và giảm $1 / 2$ luợng phân đạm vào lần bón

+ C: nghiệm thức sử dụng chế phẩm bón gốc (Bioroot) để bón lót, giảm $20 \%$ luợng phân lân bón lót và 1/2 lương phân đạm vào lần bón phân cuối.

Nguồn: Tác giả tổng hợp

* Khổ qua

- Bố trí 03 nghiệm thức, 03 lần lặp lại, diện tích ô khảo nghiệm: $60 \mathrm{~m}^{2}(\mathrm{~S}=2.5 \mathrm{~m}$ x $24 \mathrm{~m})$.

\section{Bảng 3}

Bảng tổng hợp lượng phân bón cây Khổ qua

\begin{tabular}{|c|c|c|c|c|c|c|}
\hline Nghiệm thức & $\begin{array}{c}\text { Bón lót } \\
(\mathrm{kg})\end{array}$ & $\begin{array}{c}\text { 20NSG } \\
(\mathrm{kg})\end{array}$ & $\begin{array}{c}\text { 30NSG } \\
(\mathrm{kg})\end{array}$ & $\begin{array}{c}40 \\
\text { NSG } \\
(\mathrm{kg}) \\
\end{array}$ & $\begin{array}{c}\text { 50NSG } \\
(\mathrm{kg})\end{array}$ & $\begin{array}{c}\text { 60NSG } \\
(\mathrm{kg})\end{array}$ \\
\hline \multirow{2}{*}{ ĐC } & Phân chuồng: 97 & \multirow[b]{2}{*}{$20.20 .15: 1.60$} & $\begin{array}{c}\text { Bánh dầu: } \\
1.6\end{array}$ & $\begin{array}{l}\text { Ure: } \\
0.25\end{array}$ & $\begin{array}{l}\text { Ure: } \\
0.25\end{array}$ & $\begin{array}{l}\text { Ure: } \\
0.25\end{array}$ \\
\hline & Bánh dầu: 1.60 & & $\begin{array}{c}\text { 20.20.15: } \\
1.2\end{array}$ & $\begin{array}{c}16.1 \\
6.8: \\
1.2\end{array}$ & $\begin{array}{c}16.16 .8 \\
: 1.2\end{array}$ & $\begin{array}{l}16.16 . \\
8: 1.2\end{array}$ \\
\hline
\end{tabular}




\begin{tabular}{|c|c|c|c|c|c|c|}
\hline Nghiệm thức & $\begin{array}{c}\text { Bón lót } \\
(k g)\end{array}$ & $\begin{array}{c}\text { 20NSG } \\
(\mathrm{kg})\end{array}$ & $\begin{array}{c}\text { 30NSG } \\
(\mathrm{kg})\end{array}$ & $\begin{array}{c}40 \\
\text { NSG } \\
(\mathrm{kg}) \\
\end{array}$ & $\begin{array}{c}\text { 50NSG } \\
(\mathrm{kg})\end{array}$ & $\begin{array}{l}\text { 60NSG } \\
(\mathrm{kg})\end{array}$ \\
\hline & Tro dừa: 0.80 & & $\begin{array}{l}\text { Nitrabor: } \\
0.8\end{array}$ & & & \\
\hline & $\begin{array}{l}\text { Lân Văn Điển: } \\
\qquad 6.50\end{array}$ & & & & & \\
\hline & Kali: 0.80 & & & & & \\
\hline & Ure: 0.80 & & & & & \\
\hline \multirow{6}{*}{ A } & Phân chuồng: 97 & 20.20.15: 1.60 & $\begin{array}{c}\text { Bánh dầu: } \\
1.6\end{array}$ & $\begin{array}{l}\text { Ure: } \\
0.2\end{array}$ & $\begin{array}{l}\text { Ure: } \\
0.2\end{array}$ & $\begin{array}{c}\text { Ure: } \\
0.2\end{array}$ \\
\hline & Bánh dầu: 1.60 & Bioroot: 3.00 & $\begin{array}{l}\text { 20.20.15: } \\
0.96\end{array}$ & $\begin{array}{c}16.1 \\
6.8: \\
0.96\end{array}$ & $\begin{array}{c}16.16 .8 \\
: 0.96\end{array}$ & $\begin{array}{l}16.16 . \\
8: 0.96\end{array}$ \\
\hline & Tro dừa: 0.80 & & $\begin{array}{l}\text { Nitrabor: } \\
0.64\end{array}$ & & & \\
\hline & $\begin{array}{l}\text { Lân Văn Điển: } \\
6.50\end{array}$ & & & & & \\
\hline & Kali: 0.80 & & & & & \\
\hline & Ure: 0.80 & & & & & \\
\hline \multirow{6}{*}{ B } & Phân chuồng: 97 & 20.20.15: 1.60 & $\begin{array}{c}\text { Bánh dầu: } \\
1.6\end{array}$ & $\begin{array}{l}\text { Ure: } \\
0.18\end{array}$ & $\begin{array}{l}\text { Ure: } \\
0.18\end{array}$ & $\begin{array}{l}\text { Ure: } \\
0.18\end{array}$ \\
\hline & Bánh dầu: 1.60 & Bioroot: 6.00 & $\begin{array}{c}20.20 .15: \\
0.84\end{array}$ & $\begin{array}{c}16.1 \\
6.8: \\
0.84\end{array}$ & $\begin{array}{c}16.16 .8 \\
: 0.84\end{array}$ & $\begin{array}{l}16.16 . \\
8: 0.84\end{array}$ \\
\hline & Tro dừa: 0.80 & & $\begin{array}{l}\text { Nitrabor: } \\
0.56\end{array}$ & & & \\
\hline & $\begin{array}{l}\text { Lân Văn Điển: } \\
6.50\end{array}$ & & & & & \\
\hline & Kali: 0.80 & & & & & \\
\hline & Ure: 0.80 & & & & & \\
\hline
\end{tabular}

Ghi chú:

+ NSG: ngày sau gieo;

+ ĐC: nghiệm thức đối chứng (công thức bón của nông dân);

+ A: nghiệm thức bổ sung $50 \mathrm{~kg}$ phân hũu co vi sinh Bioroot/1,000m², giảm 20\% luợng phân hóa học tù lần bón 30NSG; 
lần bón 30NSG.

+ B: nghiệm thức bổ sung 100kg phân hũu co vi sinh Bioroot/1,000m², giảm 30\% luợng phân hóa học tù

Nguồn: Tác giả tổng hợp

* Ghi nhận các chỉ tiêu:

- Năng suất;

- Hàm lượng nitrate trong rau khi sử dụng công thức phân truyền thống so với khi sử dụng các chế phẩm sinh học ở các thời điểm: 17 NSC đối với Cải ngọt; tại thời điểm cách ly với lần bón phân đạm 10 ngày đối với Húng cây; trái thương phẩm đối với Khổ qua ở thời điểm 02 , 04, 08 ngày sau khi bón đạm; Kết quả hàm lượng nitrate trong rau được so sánh theo mức giới hạn chỉ tiêu nitrat thấp nhất đối với rau trồng ngoài đồng ruộng là $2,000 \mathrm{mg} / \mathrm{kg}$ theo Thông tư 68/2010/TT- BNNPTNT Bộ Nông nghiệp và Phát triển nông thôn ngày 03 tháng 12 năm 2010 ban hành "Danh mục chỉ tiêu, mức giới hạn cho phép về an toàn vệ sinh thực phẩm đối với một số sản phẩm thực phẩm có nguồn gốc thực vật nhập khẩu, sản xuất lưu thông trong nước thuộc phạm vi quản lý của Bộ Nông nghiệp và Phát triển nông thôn."

- Số liệu được thu thập và xử lý bằng phần mềm thống kê SAS 9.1

\section{Kết quả thảo luận}

\subsection{Nghiên cứu ứng dụng chế phẩm sinh học phục vụ sản xuất rau - quả an toàn}

\section{Bảng 4}

Hiệu quả gia tăng chiều cao và năng suất rau trong việc sử dụng Bioroot

\begin{tabular}{|c|c|c|c|c|c|}
\hline $\begin{array}{c}\text { Loại } \\
\text { cây } \\
\text { trồng }\end{array}$ & $\begin{array}{c}\text { Số } \\
\text { ruộng } \\
\text { ghi } \\
\text { nhận }\end{array}$ & $\begin{array}{c}\text { So } \\
\text { sánh }\end{array}$ & $\begin{array}{c}\text { Chiều } \\
\text { cao cây } \\
\text { TB các } \\
\text { lần đo } \\
\text { (cm) }\end{array}$ & $\begin{array}{l}\text { Năng suất } \\
\left(\mathrm{kg} / 1,000 m^{2}\right)\end{array}$ & $\begin{array}{c}\text { Chênh lệch } \\
\text { năng suất (kg) }\end{array}$ \\
\hline \multirow{2}{*}{ Cải dún } & \multirow{2}{*}{03} & $\mathrm{AD}$ & 14.04 & $1,616.67$ & \multirow{2}{*}{50.00} \\
\hline & & $Đ C$ & 12.56 & $1,566.67$ & \\
\hline \multirow{2}{*}{$\begin{array}{l}\text { Cải ngọt } \\
\text { bông }\end{array}$} & \multirow{2}{*}{03} & $\mathrm{AD}$ & 11.73 & $1,316.67$ & \multirow{2}{*}{83.34} \\
\hline & & ĐC & 10.36 & $1,233.33$ & \\
\hline \multirow{2}{*}{ Cải xanh } & \multirow{2}{*}{03} & $\mathrm{AD}$ & 13.33 & $1,633.33$ & \multirow{2}{*}{50.00} \\
\hline & & ĐC & 11.96 & $1,583.33$ & \\
\hline \multirow{2}{*}{ Cải thìa } & \multirow{2}{*}{01} & $\mathrm{AD}$ & 7.80 & $1,300.00$ & \multirow{2}{*}{50.00} \\
\hline & & ĐC & 7.23 & $1,250.00$ & \\
\hline \multirow{2}{*}{ Bí hồ lô } & \multirow{2}{*}{01} & $\mathrm{AD}$ & 408.47 & 544.75 & \multirow{2}{*}{54.00} \\
\hline & & ĐC & 398.17 & 490.75 & \\
\hline \multirow{2}{*}{ Ớt } & \multirow{2}{*}{03} & $\mathrm{AD}$ & 43.62 & $1,396.67$ & \multirow{2}{*}{240.00} \\
\hline & & ĐC & 41.15 & $1,156.67$ & \\
\hline $\mathrm{Hẹ}$ & 03 & $\mathrm{AD}$ & 34.21 & $2,853.33$ & 286.67 \\
\hline
\end{tabular}




\begin{tabular}{|c|c|c|c|c|c|}
\hline \multirow[t]{2}{*}{$\begin{array}{c}\text { Loại } \\
\text { câyy } \\
\text { trồng }\end{array}$} & \multirow[t]{2}{*}{$\begin{array}{c}\text { Số } \\
\text { ruộng } \\
\text { ghi } \\
\text { nhận }\end{array}$} & $\begin{array}{c}\text { So } \\
\text { sánh }\end{array}$ & $\begin{array}{c}\text { Chiều } \\
\text { cao cây } \\
\text { TB các } \\
\text { lần đoo } \\
\text { (cm) }\end{array}$ & $\begin{array}{l}\text { Năng suất } \\
\left(\mathrm{kg} / 1,000 m^{2}\right)\end{array}$ & \multirow[t]{2}{*}{$\begin{array}{c}\text { Chênh lệch } \\
\text { năng suất (kg) }\end{array}$} \\
\hline & & ĐC & 33.33 & $2,566.67$ & \\
\hline \multirow{2}{*}{ Cải tùa xại } & 02 & $\mathrm{AD}$ & 46.02 & $2,853.33$ & \multirow{2}{*}{286.67} \\
\hline & & ĐC & 43.32 & $2,566.67$ & \\
\hline \multirow{2}{*}{ Đậu cove } & \multirow{2}{*}{03} & $\mathrm{AD}$ & 534.87 & 589.00 & \multirow{2}{*}{84.89} \\
\hline & & ĐC & 506.41 & 504.11 & \\
\hline \multirow{2}{*}{ Cải bắp } & \multirow{2}{*}{03} & $\mathrm{AD}$ & 54.09 & $2,317.33$ & \multirow{2}{*}{740.00} \\
\hline & & ĐC & 49.41 & $1,577.33$ & \\
\hline \multirow{2}{*}{ Dưa hấu } & & $\mathrm{AD}$ & 485.31 & $2,190.00$ & \multirow{2}{*}{151.67} \\
\hline & 03 & ĐC & 465.22 & $2,038.33$ & \\
\hline
\end{tabular}

Nguồn: H. T. H. Nguyen (2010)

Kết quả ở Bảng 4 cho thấy sự gia tăng chiều cao trung bình của cây ở các ruộng có sử dụng Bioroot $(\mathrm{AD})$ đều cao hơn so với ruộng đối chứng không sử dụng $(\mathrm{BC})$; bên cạnh đó, các ruộng $\mathrm{AD}$ cũng đều cho năng suất cao hơn so với các ruộng $\mathrm{ĐC}$. Như vậy, việc sử dụng Bioroot để bón lót vào giai đoạn làm đất trước khi trồng giúp kích thích sự tăng trưởng của cây rau, dẫn đến gia tăng năng suất từ $50-740 \mathrm{~kg} / 1,000 \mathrm{~m}^{2}$ (tăng khoảng 3.1-31.9\%) tùy theo chủng loại rau, phù hợp với kết quả nghiên cứu của Pham (2007) là việc sử dụng chế phẩm sinh học và phân bón tạo bởi chế phẩm vi sinh đã giúp sản lượng rau tăng từ 15-20\%.

\section{Bảng 5}

Hiệu quả hạn chế bệnh, chết cây trong việc sử dụng Bioroot

\begin{tabular}{|c|c|c|c|c|c|c|c|c|c|c|}
\hline \multirow[t]{2}{*}{$\begin{array}{l}\text { Loại cây } \\
\text { trồng }\end{array}$} & \multirow{2}{*}{$\begin{array}{c}\text { Số } \\
\text { ruộng } \\
\text { ghi } \\
\text { nhận }\end{array}$} & \multicolumn{3}{|c|}{$\begin{array}{c}T y \hat{~ l e ̣ ̂ ~ b e ̣ ̂ n h ~-~ c h e ̂ ́ t ~ c a ̂ y ~} \\
(\%)\end{array}$} & \multicolumn{3}{|c|}{$\begin{array}{c}\text { Lự̆ng phân hóa học } \\
\text { sû̉ dung (*) } \\
\left(\mathrm{kg} / 1,000 \mathrm{~m}^{2}\right) \\
\end{array}$} & \multicolumn{3}{|c|}{ Năng suất $\left(\mathrm{kg} / 1,000 \mathrm{~m}^{2}\right)$} \\
\hline & & $A D$ & $\boldsymbol{\oplus C}$ & $\begin{array}{c}\text { Chênh } \\
\text { lệch }\end{array}$ & $A D$ & $\boldsymbol{\oplus C}$ & $\begin{array}{c}\text { Chênh } \\
\text { lệch }\end{array}$ & $A D$ & $\boldsymbol{\oplus C}$ & $\begin{array}{c}\text { Chênh } \\
\text { lệch }\end{array}$ \\
\hline Mồng tơi & 03 & $1.33^{\mathrm{a}}$ & $6.00^{\mathrm{b}}$ & 4.67 & 17.67 & 21.00 & 3.33 & $2,167^{\mathrm{a}}$ & $1,633^{\mathrm{a}}$ & 533 \\
\hline $\begin{array}{l}\text { Củ cải } \\
\text { trắng }\end{array}$ & 03 & $3.33^{\mathrm{a}}$ & $8.00^{\mathrm{b}}$ & 4.67 & 52.33 & 47.67 & 4.67 & $3,600^{\mathrm{a}}$ & $3,133^{\mathrm{a}}$ & 467 \\
\hline Đậu cove & 03 & $2.67^{\mathrm{a}}$ & $8.00^{\mathrm{b}}$ & 5.33 & 58.33 & 93.33 & 35.00 & $3,233^{\mathrm{a}}$ & $2,933^{\mathrm{a}}$ & 300 \\
\hline Ngò rí & 03 & $11.07^{\mathrm{a}}$ & $25.40^{\mathrm{b}}$ & 14.33 & 21.67 & 21.67 & - & $433^{\mathrm{a}}$ & $343^{\mathrm{a}}$ & 90 \\
\hline Dưa hấu & 03 & $2.67^{\mathrm{a}}$ & $12.00^{\mathrm{b}}$ & 9.33 & 82.00 & 82.00 & - & $2,467^{\mathrm{b}}$ & $2,167^{\mathrm{a}}$ & 300 \\
\hline Dưa leo & 03 & $1.33^{\mathrm{a}}$ & $5.33^{\mathrm{b}}$ & 4.00 & 41.00 & 71.67 & 30.67 & $3,200^{\mathrm{a}}$ & $2,600^{\mathrm{a}}$ & 600 \\
\hline
\end{tabular}




\begin{tabular}{|c|c|c|c|c|c|c|c|c|c|c|}
\hline \multirow[t]{2}{*}{$\begin{array}{l}\text { Loại cây } \\
\text { trồng }\end{array}$} & \multirow{2}{*}{$\begin{array}{c}\text { Số } \\
\text { ruộng } \\
\text { ghi } \\
\text { nhận }\end{array}$} & \multicolumn{3}{|c|}{$\begin{array}{c}\text { Tỷ lệ bệnh - chết cây } \\
(\%)\end{array}$} & \multicolumn{3}{|c|}{$\begin{array}{c}\text { Lựng phân hóa học } \\
\text { sử dụng (*) } \\
\left(\mathrm{kg} / 1,000 \mathrm{~m}^{2}\right)\end{array}$} & \multicolumn{3}{|c|}{ Năng suất $\left(\mathrm{kg} / 1,000 \mathrm{~m}^{2}\right)$} \\
\hline & & $A D$ & $\boldsymbol{D C}$ & $\begin{array}{l}\text { Chênh } \\
\text { lệch }\end{array}$ & $D$ & $\boldsymbol{D C}$ & $\begin{array}{c}\text { Chênh } \\
\text { lệch }\end{array}$ & $A D$ & $\boldsymbol{D C}$ & $\begin{array}{c}\text { Chênh } \\
\text { lệch }\end{array}$ \\
\hline Rau cần & 03 & $5.33^{\mathrm{a}}$ & $15.33^{\mathrm{b}}$ & 10.00 & 23.67 & 39.67 & 16.00 & $2,263^{\mathrm{a}}$ & $1,810^{\mathrm{a}}$ & 453 \\
\hline Rau quế & 03 & $3.33^{\mathrm{a}}$ & $7.33^{\mathrm{a}}$ & 4.00 & 73.33 & 133.33 & 60.00 & $2,347^{\mathrm{a}}$ & $1,853^{\mathrm{a}}$ & 493 \\
\hline Cải tùa xại & i 03 & $5.33^{\mathrm{a}}$ & $8.67^{\mathrm{a}}$ & 3.33 & 52.67 & 64.33 & 11.67 & $2,750^{\mathrm{a}}$ & $2,300^{\mathrm{a}}$ & 450 \\
\hline Khổ qua & 03 & $6.00^{\mathrm{a}}$ & $12.00^{\mathrm{b}}$ & 6.00 & 55.67 & 89.00 & 33.33 & $3,067^{\mathrm{a}}$ & $2,683^{\mathrm{a}}$ & 383 \\
\hline Cà chua & 03 & $8.67^{\mathrm{a}}$ & $15.33^{\mathrm{b}}$ & 6.67 & 67.00 & 90.33 & 23.33 & $3,573^{\mathrm{b}}$ & $3,110^{\mathrm{a}}$ & 463 \\
\hline
\end{tabular}

Ghi chú:

- Trong cùng một cột, các giá trị được biểu thị bởi những chữ cái giống nhau thì khác nhau không có ý nghĩa theo phân tích thống kê ANOVA (ở mức độ tin cậy 95\%);

- (*) Loại phân sử dụng: DAP, UREA, NPK.

Nguồn: H. T. H. Nguyen (2010)

Qua Bảng 5 cho thấy ở các ruộng $\mathrm{AD}$ đều có tỷ lệ cây bệnh, cây chết thấp hơn so với ruộng ĐC trung bình từ 3.33-14.33\% (tùy theo loại). Ngoài ra, năng suất của các ruộng $\mathrm{AD}$ cũng đều cao hơn so với ruộng ĐC, ngay cả ở các hộ (27/33) mạnh dạn cắt giảm lượng phân hóa học DAP, Urea, NPK sử dụng ở ruộng AD trung bình là $242.2 \mathrm{~kg} /$ ha cũng đều cho năng suất cao hơn ruộng ĐC.

Qua ghi nhận thực tế, ruộng rau có bón Bioroot kích thích cây phát triển xanh tốt; lá dày; thân cây khỏe, cứng cáp hơn; chống chọi tốt với điều kiện khắc nghiệt của thời tiết trong mùa mưa; giảm được tỷ lệ chết cây con, tỷ lệ bệnh héo rũ, cháy lá, bệnh khảm, bệnh nứt thân, chạy dây trên cây họ bầu bí; giúp tăng năng suất, tăng lợi nhuận hơn so với ruộng đối chứng trên cùng một đơn vị diện tích. Có được kết quả như vậy vì là ngoài thành phần phân hữu cơ và các chất vi lượng cần thiết, trong Bioroot còn có chứa nhóm VSV chức năng có khả năng cố định đạm; VSV phân giải các hợp chất lân khó tan thành các hợp chất lân hòa tan mà cây trồng dễ dàng hấp thu; VSV phân giải Cellulose làm thúc đẩy quá trình phân hủy Cellulose được triệt để và nhanh chóng thành các chất hữu cơ bón vào đất, giúp cho đất tơi xốp, tăng độ màu mỡ của đất tạo điều kiện nâng cao năng suất cây trồng và chất lượng nông sản; nhóm VSV ức chế VSV gây bệnh vùng rễ. Ngoài ra còn có nấm đối kháng Trichoderma không những có khả năng tiêu diệt các loài nấm gây hại rễ (như Phytophthora, Fusarium, Rhizoctonia solani, ...) mà nó còn có khả năng phân hủy Cellulose, phân giải lân chậm tan. Đặc biệt trong thành phần của Bioroot còn có thảo mộc chứa một hàm lượng Saponin - yếu tố rất hiệu quả trong phòng trừ tuyến trùng hại vùng rễ. Từ đó giúp cây trồng sinh trưởng mạnh, tăng năng suất, chống chịu tốt với điều kiện bất lợi của môi trường.

Kết quả này phù hợp với kết quả nghiên cứu của L. T. M. Tran, Nguyen, và Chu (2019) khi so sánh với các công thức chỉ bón lót với NPK và phân chuồng ủ, phân hữu cơ biochar có tác động tốt tới một số chỉ tiêu sinh trưởng và chất lượng của cây cải ngọt.

3.2. Nghiên cứu úng dụng các loại chế phẩm sinh học, trong đó có Bioroot, nhằm giảm lự̣ng phân Ure (đạm) bón cho các loại rau ăn lá, rau gia vị, rau ăn quả 


\section{* Cải ngọt}

Theo dõi năng suất của năm chế độ bón phân khác nhau, kết quả thu thập (Bảng 6) cho thấy năng suất cải ngọt dao động từ 48.18-57.15tấn/ha và không có sự khác biệt có ý nghĩa thống kê giữa các nghiệm thức. Điều này cho thấy việc sử dụng các loại phân, chế phẩm sinh học (phân gà xủ lý Humix, Agribio, Bioroot và bioking) và giảm tổng lượng phân đạm hay ở kỳ bón phân đạm cuối trong các nghiệm thức đều không làm ảnh hưởng đến năng suất của cây cải ngọt. Kết quả này tương tự với kết quả nghiên cứu của Cao, Nguyen, Nguyen, và Tran (2011) cho thấy bón phân hữu cơ vi sinh cho rau xanh không những tiết kiệm phân nửa lượng phân hóa học mà còn không làm giảm năng suất và vẫn đảm bảo chất lượng sản phẩm.

\section{Bảng 6}

Năng suất cải ngọt và hàm lượng nitrat ở 17 NSC

\begin{tabular}{ccc}
\hline Nghiệm thức & $\begin{array}{c}\text { Năng suất } \\
\text { (tấn/ha) }\end{array}$ & $\begin{array}{c}\text { Hàm lượng nitrat ở 17 NSC } \\
(\mathbf{m g} / \mathbf{k g})\end{array}$ \\
\hline ĐC & $52.71^{\mathrm{a}} \pm 8,808$ & $1,121.3$ \\
$\mathrm{~A}$ & $57.15^{\mathrm{a}} \pm 9,827$ & 1,889 \\
$\mathrm{~B}$ & $48.18^{\mathrm{a}} \pm 4,072$ & 2,419 \\
$\mathrm{C}$ & $52^{\mathrm{a}} \pm 4,924$ & $1,621.3$ \\
$\mathrm{D}$ & $51.56^{\mathrm{a}} \pm 1.0$ & $1,299.3$ \\
\hline
\end{tabular}

Ghi chú: Các số liệu có cùng chữ số theo sau trong cùng một cột thì khác biệt không ý nghĩa mức ý nghĩa 95\%; (*): Trung bình 03 lần lặp lại

Nguồn: T. H. Nguyen và Vo (2015)

Kết quả hàm lượng nitrat của các nghiệm thức $\mathrm{ĐC}, \mathrm{A}, \mathrm{C}, \mathrm{D}$ đều nằm trong ngưỡng cho phép (Bảng 6). Kết quả của nghiệm thức $\mathrm{B}$ (Agribio) vượt ngưỡng cho phép.

Tổng hợp kết quả về năng suất và hàm lượng nitrat thì chế độ phân bón của nghiệm thức đối chứng, phân gà xử lý Humix, Bioroot và bioking được khuyến cáo sử dụng. Nghiên cứu của L. T. M. Tran và cộng sự (2019) cũng cho kết quả phân ủ hữu cơ biochar làm giảm đáng kể hàm lượng nitrat trong lá cây cải ngọt.

* Húng cây

Theo dõi năng suất của bốn chế độ bón phân khác nhau, kết quả thu thập (Bảng 7) cho thấy năng suất húng cây dao động từ 21.4-22 tấn/ha và không có sự khác biệt có ý nghĩa thống kê giữa các nghiệm thức. Điều này cho thấy việc sử dụng các loại phân, chế phẩm sinh học (phân gà xủ lý Humix, Agribio, Bioroot) và giảm tổng lượng phân đạm hay ở kỳ bón phân đạm cuối trong các nghiệm thức đều không làm ảnh hưởng đến năng suất của cây húng cây.

\section{Bảng 7}

Năng suất rau húng cây và hàm lượng nitrat ở 43 NSC

Nghiệm thức

Năng suất

(tấn/ha)

$21.4^{\mathrm{a}} \pm 2.6$
Hàm lượng nitrat ở 10 ngày sau bón đạm(*) (mg/kg)

ĐC

644 
Nghiệm thức

Năng suất

(tấn/ha)
Hàm lượng nitrat ở 10 ngày sau bón đạm ${ }^{(*)}$

(mg/kg)
A
$22.0^{\mathrm{a}} \pm 4.0$
630
B
$21.7^{\mathrm{a}} \pm 3.5$
696
C
$21.5^{\mathrm{a}} \pm 1.5$
565

Ghi chú: Các số liệu có cùng chữ số theo sau trong cùng một cột thì khác biệt không ý nghĩa mức ý nghĩa 95\%, (*): Trung bình 03 lần lặp lại

Nguồn: T. H. Nguyen và Vo (2015)

Cùng với kết quả hàm lượng nitrat của các nghiệm thức đều nằm trong ngưỡng cho phép (Bảng 7). thì chế độ phân bón của nghiệm thức đối chứng, phân gà xử lý Humix, Agribio, Bioroot được khuyến cáo sử dụng.

Kết quả này tương tự với kết quả nghiên cứu của Cao và cộng sự (2011) cho thấy đối với rau gia vị, bón 15 đến 30 tấn phân hữu cơ vi sinh/ha và $50 \mathrm{~N}-42.5 \mathrm{P}_{2} \mathrm{O}_{5}-20 \mathrm{~K}_{2} \mathrm{O} \mathrm{kg} /$ ha cho năng suất tương đương với rau bón $100 \mathrm{~N}-85 \mathrm{P}_{2} \mathrm{O}_{5}-40 \mathrm{~K}_{2} \mathrm{O} \mathrm{kg} / \mathrm{ha}$; bón 15 đến 30 tấn phân phân hữu cơ vi sinh /ha $80 \mathrm{~N}-47 \mathrm{P}_{2} \mathrm{O}_{5}-20 \mathrm{~K}_{2} \mathrm{O} \mathrm{kg} / \mathrm{ha}$ cho năng suất tương đương với bón $160 \mathrm{~N}-94 \mathrm{P}_{2} \mathrm{O}_{5}$ $40 \mathrm{~K}_{2} \mathrm{O} \mathrm{kg} / \mathrm{ha}$ cho hành lá nhưng hàm lượng nitrat thấp.

* Khổ qua

Sau 19 lần thu hoạch, kết quả khảo nghiệm thể hiện năng suất đạt được của các nghiệm thức không khác biệt có ý nghĩa thống kê (Bảng 8).

\section{Bảng 8}

Năng suất khổ qua (19 lần thu hoạch) của các nghiệm thức và hàm lượng nitrate trên trái khổ qua ở các thời điểm khác nhau sau khi bón đạm

\begin{tabular}{ccccc}
\hline Nghiệm thức & Năng suất (tấn/ha) & \multicolumn{3}{c}{ Hàm lưọng nitrat sau khi bón đạm } \\
$(\mathbf{m g} / \mathbf{k g})^{(*)}$
\end{tabular}

Ghi chú: Các số liệu có cùng chữ số theo sau trong cùng một cột thì khác biệt không ý nghĩa mức ý nghĩa $95 \%$, (*): Trung bình 03 lần lặp lại

Nguồn: T. H. Nguyen và Vo (2015)

Mẫu khổ qua được lấy kiểm tra chỉ tiêu nitrat được lấy để kiểm tra hàm lượng nitrat cho thấy hàm lượng nitrat trên các mẫu khổ qua của các nghiệm thức đều đạt yêu cầu về hàm lượng nitrat ở các thời điểm 02, 04, 08 ngày sau khi bón phân đạm. So với đối chứng bón theo nông dân, sử dụng Bioroot giúp giảm lượng phân đạm bón cho cây mà không làm ảnh hưởng năng suất, góp phần giảm ô nhiễm môi trường.

Kết quả nghiên cứu này tương tự với kết quả thí nghiệm của L. V. Nguyen và Cao (2012) cho thấy việc sử dụng phân bón vi sinh góp phần tiết kiệm từ $25 \%$ phân bón hóa học cho đậu bắp và 
ớt sừng vàng, đến $50 \%$ phân bón hóa học cho cà sọc lem lai mà năng suất vẫn tương đương với nghiệm thức bón $100 \%$ phân hóa học. Đồng thời phẩm chất sản phẩm từ các nghiệm thức sử dụng phân bón vi sinh được cải thiện thông qua hàm lượng nitrate trong quả thấp hơn nghiệm thức bón 100\% phân hóa học.

\section{Kết luận}

Chế phẩm bón gốc (Phân hữu cơ vi sinh Bioroot) là một sản phẩm khoa học công nghệ được chuyển giao thông qua một dự án nông thôn miền núi từ cơ quan nghiên cứu ứng dụng cấp trung ương (Trung tâm Đấu tranh sinh học - Viện Bảo vệ thực vật) xuống cơ quan nghiên cứu ứng dụng cấp địa phương (Trung tâm Kỹ thuật và Công nghệ sinh học - Sở Khoa học và Công nghệ Tiền Giang). Trong thời gian dài, sản phẩm đã được địa phương tiếp nhận, thử nghiệm, nghiên cứu ứng dụng trên nhiều chủng loại rau và trên nhiều địa bàn khác nhau cho thấy sự phù hợp của sản phẩm với điều kiện thổ nhưỡng, thời tiết, khí hậu của vùng Đồng bằng sông Cửu Long, giúp tăng năng suất, chất lượng rau, giảm sâu bệnh hại, giảm hàm lượng nitrat trong sản phẩm rau, phù hợp với các tiêu chí sản xuất an toàn vệ sinh thực phẩm của tiêu chuẩn VietGAP.

Từ tháng 11/2017, Trung tâm Kỹ thuật và Công nghệ sinh học đã triển khai dự án sản xuất thử nghiệm "Hoàn thiện và nhân rộng mô hình canh tác rau ứng dụng công nghệ thủy canh và sử dụng giá thể hữu cơ phục vụ nhu cầu phát triển nông nghiệp công nghệ cao, nông nghiệp đô thị của tỉnh Tiền Giang" (L. T. X. Nguyen, 2021), trong đó có mục tiêu hoàn thiện quy trình thiết bị và công nghệ sản xuất phân hữu cơ, hữu cơ vi sinh và giá thể hữu cơ, công suất tối thiểu 05 tấn/ngày để có khả năng sản xuất số lượng lớn sản phẩm Bioroot đáp ứng nhu cầu sản xuất rau an toàn/ rau VietGAP cho các vùng sản xuất rau chuyên canh trong và ngoài tỉnh trong thời gian tới.

\section{Tài liệu tham khảo}

Bộ Nông nghiệp và Phát triển nông thôn. (2010). Thông tu số 29/2010/TT-BNNPTNT ngày 06/05/2010 của Bộ Nông nghiệp và Phát triển nông thôn về Danh mục chỉ tiêu, mức giới hạn cho phép về an toàn vệ sinh thực phẩm đối với một số sản phẩm thực phẩm có nguồn gốc thực vật nhập khẩu, sản xuất luu thông trong nước thuộc phạm vi quản lý của Bộ Nông nghiệp và Phát triển nông thôn [Circular 29/2010/TT-BNNPTNT dated 06 May 2010 by the Ministry of Agriculture and Rural development on the list of targets and permissible limits on food safety and hygiene for a number of food products of plant origin imported and produced for domestic circulation under the management of the Ministry of Agriculture and Rural development]. Retrieved October 8, 2020, from https://thuvienphapluat.vn/vanban/Thuong-mai/Thong-tu-29-2010-TT-BNNPTNT-Danh-muc-chi-tieu-muc-gioi-han-chophep-105346.aspx

Bộ Nông nghiệp và Phát triển nông thôn. (2010). Thông tur số 68/2010/TT-BNNPTNT ngày 03/12/2010 của Bộ Nông nghiệp và Phát triển nông thôn về ban hành danh muc chỉ tiêu, mức giới hạn cho phép về an toàn vệ sinh thực phẩm đối với một số sản phẩm thưc phẩm có nguồn gốc thực vật nhập khẩu, sản xuất lư thông trong nước thuộc phạm vi quản lý của Bộ Nông Nghiệp và Phát triển nông thôn [Circular No. 68/2010/TT-BNNPTNT of December 03, 2010 issuing the list of criteria and permitted limit on food hygiene and safety for some of plantderived food products imported, produced and circulated domestically under the management scope of the Ministry of Agriculture and Rural Development]. Retrieved October 8, 2020, from https://thuvienphapluat.vn/van-ban/Thuong-mai/Thong-tu-68-2010-TT-BNNPTNTDanh-muc-chi-tieu-muc-gioi-han-115546.aspx 
Cao, D. N., Nguyen, T. T., Nguyen, A. V., \& Tran, G. T. (2011). Hiệu quả của phân hữu cơ - Vi sinh trên năng suất và chất lượng rau xanh [Effect of organic fertilizer - Microbiology on yield and quality of green vegetables]. Tạp chí Khoa học Truờng Đại học Cần Tho, 18(b), $18-28$.

Ho, H. N. (2019). Úng dụng công nghệ cao trong canh tác các loại rau quy mô hộ gia đình trên địa bàn huyện Cái Bè (Báo cáo tổng kết Dự án sản xuất thử nghiệm) [Application of high technology in household-scale vegetable farming in Cai Be district (Final report of pilot production project)]. Tien Giang, Vietnam: Sở Khoa học và Công nghệ Tiền Giang.

Le, N. S. (2016). Nghiên cưu ứng dụng công nghệ cao trong sản xuất, sơ chế, đóng gói và bảo quản rau quả (Báo cáo tổng kết Đề tài nghiên cứu khoa học) [Research and apply high technology in production, preliminary processing, packaging and preservation of fruits and vegetables (Summary report of scientific research project)]. Tien Giang, Vietnam: Sở Khoa học và Công nghệ Tiền Giang.

Nguyen, H. T. H. (2010). Xây dựng mô hình sản xuất và ứng dụng chế phẩm sinh học phục vụ rau - Quả an toàn (Báo cáo tổng kết Dự án sản xuất thử nghiệm) [Building models of production and application of probiotics to serve safe vegetables and fruits (Final report of pilot production project)]. Tien Giang, Vietnam: Sở Khoa học và Công nghệ Tiền Giang.

Nguyen, L. T. X. (2021). Hoàn thiện và nhân rộng mô hình canh tác rau ứng dụng công nghệ thủy canh và sủ dụng giá thể hưu co phục vụ nhu cầu phát triển nông nghiệp công nghệ cao, nông nghiệp đô thị của tỉnh Tiền Giang (Báo cáo tổng kết Dự án Khoa học và Công nghệ) [Completing and replicating the vegetable farming model applying hydroponic technology and using organic substrates to serve the needs of developing high-tech agriculture and urban agriculture in Tien Giang province (Final Report of the Science and Technology Project)]. Tien Giang, Vietnam: Sở Khoa học và Công nghệ Tiền Giang.

Nguyen, L. V., \& Cao, D. N. (2012). Hiệu quả phân bón vi sinh đến năng suất rau xanh (rau ăn quả) trồng trên đất phù sa huyện Ô Môn Thành phố Cần Thơ [Effect of micro-fertilizers on yield of green vegetables (fruit vegetables) grown on alluvial soil in O Mon district, Can Tho City]. Tạp chí Khoa hoc Truòng Đại hoc Cần Tho, 23(a), 13-223.

Nguyen, T. H. (2018). Úng dụng công nghệ cao sản xuất rau theo hướng nông nghiệp đô thị [High-tech application of vegetable production towards urban agriculture]. Tạp chi Khoa hoc và Công nghệ Việt Nam, 8(2018), 41-42.

Nguyen, T. H., \& Vo, N. T. (2015). Xây dụng mô hình sản xuất rau an toàn đạt chứng nhận VietGAP tại 3 huyện Cần Đước, Cần Giuộc, Đức Hòa tỉnh Long An (Báo cáo tổng kết Dự án Khoa học và Công nghệ) [Building a model of safe vegetable production with VietGAP certification in 3 districts of Can Duoc, Can Giuoc, Duc Hoa, Long An province (Final Report of the Science and Technology Project)]. Long An, Vietnam: Sở Khoa học và Công nghệ Long An.

Nguyen, T. T. T. (2019). Khí canh trụ đứng - Giải pháp mới cho nông nghiệp xanh [Vertical aeroponics - New solution for green agriculture]. Tập san Khoa hoc và Công nghệ - Sở Khoa họ và Công nghệ Tiền Giang, 2(2019), 49-50.

Pham, L. X. (2007). Nghiên cưu ảnh hương của một số loại phân hũu cơ vi sinh tới năng suất, hàm luợng $\mathrm{NO}_{3}^{-}$của rau cải bắp và hóa tính đất trồng rau tại thị xã Hà Giang [Study on the effect of some microbial organic fertilizers on yield, $\mathrm{NO}_{3}{ }^{-}$content of cabbage and vegetable soil chemistry in Ha Giang town] (Master's thesis, Thai Nguyen University of Agriculture and Forestry, Thai Nguyen City, Vietnam). 
Sy Nguyen (2020). Hướng tới vùng chuyên canh nông sản an toàn [Towards an area specializing in safe agricultural production]. Retrieved October 12, 2020, from http://baoapbac.vn/kinhte/201804/huong-toi-vung-chuyen-canh-nong-san-an-toan-790901/

Tran, D. H. (2016). Nghiên cưu ứng dụng công nghệ vi sinh để sản xuất giá thể hũu cơ sạch tù phế phu liệu nông nghiệp phục vụ nhu cầu trồng hoa và rau sạch tại tỉnh Tiền Giang (Báo Báo cáo tổng kết Đề tài nghiên cứu khoa học) [Research and application of microbiological technology to produce clean organic substrates from agricultural wastes to serve the needs of growing clean flowers and vegetables in Tien Giang province (Scientific Research Project Summary Report)]. Tien Giang, Vietnam: Sở Khoa học và Công nghệ Tiền Giang.

Tran, L. T. M., Nguyen, H. T. T., \& Chu, N. T. B. (2019). Sinh trưởng và một số chỉ tiêu chất lượng của cây cải ngọt (Brassica integrifolia) dưới ảnh hưởng của phân ủ hữu cơ Biochar [Growth and quality parameters of broccoli (Brassica integrifolia) under the influence of Biochar organic compost]. Tạp chí Khoa học và Công nghệ truờng Đại học Hùng Vuơng, 14(1), 47-53.

Tran, P. H. (2019). Xây dụ̂ng mô hình canh tác rau ăn lá ưng dụng công nghệ thủy canh tại Thị trấn Chọ Gạo, Tiền Giang (Báo cáo tổng kết Dự án sản xuất thử nghiệm) [Building a model of growing leafy vegetables using hydroponic technology in Cho Gao Town, Tien Giang. (Final report of pilot production project)]. Tien Giang, Vietnam: Sở Khoa học và Công nghệ Tiền Giang.

Tran, T. T. N. (2016). Nghiên cưu úng dụng công nghệ thủy canh vào nông nghiệp đô thị Tiền Giang (Báo cáo tổng kết Đề tài nghiên cứu khoa học) [Research and application of hydroponic technology in urban agriculture in Tien Giang (Summary report of scientific research project)]. Tien Giang, Vietnam: Sở Khoa học và Công nghệ Tiền Giang. 